\title{
Self-Confident Approach in Coping with Stress and Social Appearance Anxiety of Turkish University Students: The Mediating Role of Body Appreciation
}

\author{
Orkide Bakalim ${ }^{1}$, Ph.D \\ ${ }^{1}$ Assistant Professor, Uşak University, Faculty of Education, Department of Educational Sciences, Guidance and \\ Counseling Program, 64000 UŞAK, Turkey \\ Correspondence: Orkide Bakalim, Ph.D, Assistant Professor, Uşak University, Faculty of Education, Department of \\ Educational Sciences, Guidance and Counseling Program, 64000 UŞAK, Turkey
}

Received: September 16, 2016

Accepted: October 5, 2016

Online Published: October 12, 2016

doi:10.5430/ijhe.v5n4p134

URL: http://dx.doi.org/10.5430/ijhe.v5n4p134

\begin{abstract}
During adolescence, it can be very stressful for young men and women to accept their bodies. However, it is important during this stage of their development to accept their body as it is. If they cannot complete this task successfully, young people may experience stress and anxiety. This study aims to investigate the mediating effects of body appreciation on the relationship between the self-confident approach and social appearance anxiety of Turkish female and male university students. Participants include 653 students from the Education Faculty of Uşak University (349 women, 304 men). These participants were assessed with the self-confident approach with the Ways of Coping Inventory; (WCI), Social Appearance Anxiety Scale (SAAS), and Body Appreciation Scale (BAS). Structural equation modeling (SEM) techniques were employed for assessing the mediation model. Results indicate that general body appreciation acts as a mediator in the relationship between the self-confident approach and social appearance anxiety for women, men, and the total sample.
\end{abstract}

Keywords: Body appreciation, Adolescence, Coping with stress, Self-confident approach, Social appearance anxiety, Structural equation modeling

\section{Introduction}

According to the Diagnostic and Statistical Manual of Mental Disorders, fifth edition (DSM-V) (APA, 2013), the term social anxiety disorder is used to describe individuals who have a persistent fear of performing in one or more social or performance situations. These situations subject the individuals to unfamiliar people or possible scrutiny. The individual then feels that he or she will act in an embarrassing or inappropriate way, causing humiliation. Another fear, that of negative evaluation of one's appearance, is less researched.

The definition of social appearance anxiety is given as: "the fear that one will be negatively evaluated because of one's appearance" (Claes et al., 2012; Hart et al., 2008). In previous studies (with both clinical and nonclinical samples) of body dysmorphic and eating disorder subjects, a significant and positive relationship was found between body image concerns and social appearance anxiety (Cash, Theriault, \& Annis, 2004; Çelik, Turan \& Arıc1, 2014; Coles et al., 2006; Hart et al., 2008; Pinto \& Phillips, 2005). Accordingly, social appearance anxiety can be considered to be a result of negative body image and body dissatisfaction (Sabiston, Sedgwick, Crocker, Kowalski \& Mack, 2007). Recently, the concept of appreciating one's body has been the topic of more research.

Body appreciation is defined as the positive view that an individual has about his/her body, despite body measurements and weight and any deficiencies that an individual perceives in his/herself. This view takes into account the needs of one's body, rejects any unrealistic ideals portrayed in the media, and protects one's body by maintaining a healthy lifestyle (Avalos, Tylka, \& Wood-Barcalow, 2005; Halliwell, 2013; Kroon Van Diest \& Tylka, 2010; Lannantuono \& Tylka, 2012; Ramseyer-Winter \& Satinsky, 2014; Satinsky, Reece, Dennis, Sanders \& Bardzell, 2012; Swami \& Jaafar, 2012; Tiggemann \& McCourt, 2013). In other words, body appreciation involves, beyond appreciating his/her body, a cognitive process aimed at developing and maintaining a positive view of his/her body (Avalos, Tylka, \& Wood-Barcalow, 2005; Halliwell, 2013; Swami \& Jaafar, 2012). 
A large part of being an adolescent is being concerned about physical appearance and other body characteristics, because accepting one's body is an important developmental task at this stage in one's life (Kalafat \& Kincal, 2008; Page, 1991). Nevertheless, the presentation of excessively thin models as a beauty criterion in the media may result in adolescents having less appreciation for their own bodies (Mele, Cazzato, \& Urgesi, 2013). The study conducted by Rinderknecht and Smith (2002) concluded that the weak body image and dissatisfaction were associated with depressive symptoms observed in children and adolescents. In addition, it was determined that the body image dissatisfaction is a predictor of suicidal ideation among adolescent boy and girls (Kim \& Kim, 2009).

Although the negative body perception that is widely seen among young people is thought to be a problem only in Western societies, this issue, remarkably, is nowadays found all over the world (Swami, Mada, \& Tovée, 2012). With the impact of globalization, modernization, and the social media, Turkey has started importing the social habits of Western societies. As a result of the emphasis of the Western media on slimness and physical appearance, body dissatisfaction has increased among Turkish people (Doğan, Sapmaz \& Totan, 2011). This problem can be seen in Turkish young people of age 18 to 21 years (Erol, Toprak \& Yazıc1, 2006; Güler, 2015; Kurtuluş, 2014; Özmen et al., 2007; Yumurtac1, 2012). As has been shown, a negative body image can have an adverse effect on an individual's quality of life and mental health. Despite this knowledge, few studies exist which focus on how young women and men cope with social appearance anxiety (Kowalski, Mack, Crocker, Niefer \& Fleming, 2006).

It has been noted that adolescents may utilize cognitive and behavioral strategies to adjust to or cope with thoughts, feelings, or situations that bring them distress (Cash, Santos \& Williams, 2005; Jauregui-Lobero \& Rios, 2011; Sabiston et al., 2007). Basically, two types of coping are problem-focused coping and emotion-focused coping. Problem-focused/active coping styles generally include individual's taking responsibility against the source of stress, questioning his/her own role, self-observation and re-evaluation of his/her current situation. For example self-confident approach is one of these active and efficient coping styles. Emotion-focused passive coping styles are nonfunctional attitudes and behaviors such as denial, self-reproach, alienation, neurotic thoughts and connivance (Folkman \& Lazarus, 1980). In the context of a potential threat or challenge to one's body image the most commonly reported coping strategies were behavioral avoidance (41.5\% of females and $33.2 \%$ of males), appearance management (39.9\% females, $24.4 \%$ males), social support (22.1\% females, $17.1 \%$ males), cognitive avoidance ( $20.4 \%$ females, $18.7 \%$ males), and acceptance (19.6\% females, 29.0\% males) (Kowalski et al., 2006). Moreover, a study conducted by Avalos, Tylka \& Wood-Barcalow (2005) showed a positive and significant relationship between a proactive coping style and body appreciation. Nevertheless, few studies have examined the way in which Turkish young people cope with body concerns (Doğan, Sapmaz \& Totan, 2011). In a study conducted by Gücüyeter (2003), it was established that when adolescents used effective coping strategies, such as problem-solving and searching for social support, their self-acceptance levels increased; in contrast, however, when they used ineffective strategies such as avoidance their self-acceptance levels decreased.

\subsection{Purpose and Hypotheses}

The general aim of this study is to investigate the mediating effect of body appreciation on the relationship between the self-confident approach (sub-scale of ways of coping) and social appearance anxiety of Turkish female and male university students. Accordingly, the hypotheses of the study are as follows:

Hypothesis 1. A self-confident approach is positively related to body appreciation.

Hypothesis 2. A self-confident approach is negatively related to social appearance anxiety.

Hypothesis 3 . Social appearance anxiety is negatively related to body appreciation.

Hypothesis 4. Body appreciation mediates the relationship between the self-confident approach and social appearance anxiety.

\section{Method}

\subsection{Participants}

Participants were 653 students from the Education Faculty of Uşak University (349 women and 304 men), who were between 17 and 24 years of age $($ Mwomen $=19.66$, SDwomen $=1.36$; Mmen = 19.99, SDmen $=1.45)$. Study data were collected for academic year 2014-15. The research was approved by the faculty administration. Before administering the questionnaire, researchers explained the purpose of the study to the participants, and also encouraged the participants to answer as candidly and sincerely as possible, since this was important for the validity of the study. Participants were also informed that all responses would be kept confidential. The 653 participants completed two 
measurements and a questionnaire on demographic data (gender, age, grade level, and department). Application of the measurement tools within the scope of the study took about 15-20 min.

\subsection{Measures}

\subsubsection{Self-Confident Approach (Ways of Coping Inventory)}

The original Ways of Coping Inventory (WCI) scale of 66 items was developed by Lazarus and Folkman (1984). Şahin and Durak (1995) adapted the scale for use with a Turkish population. The adapted scale comprises 30 items and 5 -factor subscales. These subscales were self-confident approach, optimistic approach, and social support approach as effective ways of coping, and helpless approach and submissive approach as ineffective ways of coping. Each subscale score is calculated separately. The subscale self-confident approach that was used in the present study comprises 7 items. The items were rated on a four-point Likert scale ranging from 1 ("strongly disagree") to 4 ("strongly agree"). The alpha coefficient was .80 .

\subsubsection{Social Appearance Anxiety Scale}

The Social Appearance Anxiety Scale (SAAS) was created by Hart et al. (2008) in order to quantify an individual's social appearance anxiety, and was translated into Turkish by Doğan (2010). A total of 340 university students (143 female, 197 male) were included in the adaptation study. The short version of the Fear of Negative Evaluation Scale (FNES) was used to evaluate criterion validity. Exploratory and confirmatory factor analyses were conducted to reveal the factor structure of the SAAS. Factor analysis results revealed the one-dimensional structure of the scale, as in its original version. For the SAAS, a Cronbach's alpha internal consistency coefficient of .93 was found; a test-retest reliability coefficient of .85 was found; and a reliability coefficient of .88 , calculated by split-half test method, was found. Item-total correlation coefficients of the Turkish version of the scale were concluded to be between .32 and .82 . The correlation between the SAAS and the FNES was demonstrated to be 60 .

\subsubsection{Mediator: Body Appreciation Scale}

The Body Appreciation Scale (BAS), which aims to measure to what extent an individual appreciates his/her own body, accepts it as it is, and takes care of it despite the ideal body measures presented by the media, was developed by Avalos, Tylka, and Wood-Barcalow (2005). The tool uses 13 items to measure each participant's positive body image. The participants are asked to rate a series of statements ( $1=$ Never, $5=$ Always), with higher scores representing greater body appreciation. Thus, the Cronbach's alpha internal consistency was found to be .94 , and the test-retest reliability coefficient was found to be .90 . In the adaptation studies, BAS was observed to have a single-factor structure in western societies (Avalos, Tylka \& Wood-Barcalow, 2005; Jauregui-Lobera \& Rios, 2011; Swami, Özgen, Gökçen \&Petrides, 2015), whereas, exhibited a two-factor structure in non-western societies (Swami \& Chamorro-Premuzic, 2008; Swami et al., 2011; Swami \& Jaafar, 2012; Swami, Mada \& Tovee, 2012; Ng, Barron \& Swami, 2015). The first adaptation study for Turkish people was conducted by Swami et al., 2015 with a sample of 501 female university students. In the factor analysis conducted in the same study, the BAS was concluded to be one-dimensional, as in Western societies. Bakalım \& Taşdelen-Karçkay (2016) performed a second study of the factor structure and a psychometric evaluation of the BAS among Turkish female and male university students. The results of a competing model analysis showed that a two-factor model (Factor $1=$ General Body Appreciation; Factor $2=$ Body Image Investment) with four items deleted (Ng, Barron, and Swami, 2015) was the best of proposed models. In the present adaptation study, for women population the Cronbach's alpha internal coefficient was found to be .89 for Factor 1 (General Body Appreciation) and .62 for factor 2 (Body Image Investment); for men population the Cronbach's alpha internal coefficient was found to be .90 for Factor 1 (General Body Appreciation) and .65 for factor 2 (Body Image Investment).

\subsection{Data Analysis}

Descriptive analysis (mean, standard deviations, range) and correlations for each scale using SPSS version 18.00 were computed. Moreover, to test the direct and indirect effects of self-confident approach on social appearance anxiety with body appreciation as a mediator, AMOS 21.0 was utilized to present the path analysis of the direct and indirect effects among all of the variables. Moreover, for the statistical evaluation of structural equation modeling (SEM), some of the indices of goodness of fit, such as the Incremental Fit Index (IFI), Comparative Fit Index (CFI), Tucker-Lewis Index (TLI), and Root Mean Square Error of Approximation (RMSEA) were calculated. 


\section{Results}

\subsection{Descriptive Statistics and Intercorrelations}

Table 1 illustrates the descriptive statistics and intercorrelations of all the study variables. It clearly shows that the self-confident approach correlates positively to General Body Appreciation and Body Image Investment, and correlates negatively to Social Appearance Anxiety. In addition, it can be seen that social appearance anxiety is negatively correlated to body appreciation.

Table 1. Descriptive statistics (means, standard deviations, range, and correlations) for all measures

\begin{tabular}{llllllll}
\hline & $\mathrm{M}$ & SD & Range & 1 & 2 & 3 & 4 \\
\hline $\begin{array}{l}\text { 1.Self-Confident } \\
\text { Approach }\end{array}$ & 21.99 & 3.57 & $10-28$ & & & \\
$\begin{array}{l}\text { 2.BAS } 1 \quad \text { (General } \\
\text { Body Appreciation) }\end{array}$ & 29.48 & 4.89 & $8-35$ & $.257^{* *}$ & & \\
$\begin{array}{l}\text { 3.BAS 2 (Body Image } \\
\text { Investment) }\end{array}$ & 7.18 & 2.15 & $2-10$ & $.098^{* *}$ & $.404^{* *}$ & & \\
$\begin{array}{l}\text { 4.Social Appearance } \\
\text { Anxiety }\end{array}$ & 34.42 & 12.22 & $16-79$ & $-.280^{* *}$ & $-.395^{* *}$ & $-.230^{* *}$ & \\
\hline
\end{tabular}

Note $* * \mathrm{p}<.05$

\subsection{Structural Model Analysis}

SEM techniques were used to assess the structural relationships among all study variables (self-confident approach, general body appreciation, body image investment and social appearance anxiety). The results showed that partially mediated model with all study variables fitted well to the data (see table 2). The suitability results were first evaluated using the ratio of the chi-square value to degrees of freedom, which must be less than 3 in this context (Kline, 2013). In this study, the ratio indicated a good fit for women, men, and the total sample. Five indices were computed to evaluate the goodness of fit of the model. According to $\mathrm{Hu}$ and Bentler (1999), Beauducel and Wittmann (2005), and Schreiber et al. (2006), an acceptable fit to the data is indicated by IFI, CFI, TLI, and AGFI values close to .90, and RMSEA values close to .06 (Beauducel \& Wittmann, 2005; Hu \& Bentler, 1999). The model is shown in Figure 1. This model showed where the self-confident approach predicts general body appreciation and body image investment, and then all these variables predict the outcome (social appearance anxiety). Test of parameter estimates showed that coefficients of direct paths were all significant, except the following path from self-confident approach to body image investment and body image investment to social appearance anxiety for both gender (see Figure 1 A, B). All the paths are significant for total sample (see Figure 1-C).

Table 2. Summary of fit indices of partial model

\begin{tabular}{llllllll}
\hline Sample & $\chi^{2}$ & df & $\chi 2 / \mathrm{df}$ & IFI & CFI & TLI & RMSEA \\
\hline Women & 1190.812 & 454 & 2.62 & .90 & .90 & .90 & .06 \\
\hline Men & 819.487 & 454 & 1.81 & .92 & .92 & .92 & .05 \\
\hline Total & 1357.735 & 453 & 2.99 & .93 & .92 & .92 & .05
\end{tabular}

The results from the path analysis were presented in Table 3. Test of parameter estimates showed that coefficients of direct paths were all significant for total sample but for women and men samples the paths from self-confident approach to body image investment and body image investment to social appearance anxiety were not significant. 
Table 3. Path coefficients for women, men and total sample

\begin{tabular}{|c|c|c|c|c|}
\hline Path & $\beta$ & $\mathrm{SE}$ & $\mathrm{CR}$ & $\mathrm{P}$ \\
\hline \multicolumn{5}{|l|}{ Women $(n=431)$} \\
\hline $\mathrm{SCA} \rightarrow \mathrm{BAS} 1$ & .334 & .095 & 3.53 & $* * *$ \\
\hline $\mathrm{SCA} \rightarrow \mathrm{BAS} 2$ & .153 & .156 & .981 & $.327^{\mathrm{NS}}$ \\
\hline $\mathrm{BAS} 1 \rightarrow \mathrm{SAA}$ & -.177 & .041 & -.4 .222 & $* * *$ \\
\hline $\mathrm{BAS} 2 \rightarrow \mathrm{SAA}$ & -.016 & .023 & -.712 & $.476^{\mathrm{NS}}$ \\
\hline $\mathrm{SCA} \rightarrow \mathrm{SAA}$ & -.154 & .047 & -3.262 & $.001 * *$ \\
\hline \multicolumn{5}{|l|}{$\operatorname{Men}(n=310)$} \\
\hline $\mathrm{SCA} \rightarrow \mathrm{BAS} 1$ & .747 & .147 & 5.095 & $* * *$ \\
\hline $\mathrm{SCA} \rightarrow \mathrm{BAS} 2$ & .410 & .225 & 1.824 & $.068^{\mathrm{NS}}$ \\
\hline BAS $1 \rightarrow$ SAA & -.136 & .047 & -2.881 & $.004 * *$ \\
\hline $\mathrm{BAS} 2 \rightarrow \mathrm{SAA}$ & -.048 & .025 & -1.903 & $.057^{\mathrm{NS}}$ \\
\hline $\mathrm{SCA} \rightarrow \mathrm{SAA}$ & -.261 & .083 & -3.155 & $.002 * *$ \\
\hline \multicolumn{5}{|l|}{ Total $(n=741)$} \\
\hline $\mathrm{SCA} \rightarrow \mathrm{BAS} 1$ & .514 & .080 & 6.385 & $* * *$ \\
\hline $\mathrm{SCA} \rightarrow \mathrm{BAS} 2$ & .257 & .131 & 1.965 & $.049 *$ \\
\hline BAS $1 \rightarrow$ SAA & -.155 & .030 & -5.155 & $* * *$ \\
\hline $\mathrm{BAS} 2 \rightarrow \mathrm{SAA}$ & -.034 & .016 & -2.088 & $.037 *$ \\
\hline $\mathrm{SCA} \rightarrow \mathrm{SAA}$ & -.189 & .043 & -4.425 & $* * *$ \\
\hline
\end{tabular}

Note. SCA. $=$ Self Confident Approach, BAS $1=$ General Body Appreciation, BAS $2=$ Body Image Investment, $\mathrm{SAA}=$ Social Appearance Anxiety, NS= Not significant, $* p<0.05 ; * * p<0.005 ; * * *<0.001$

A
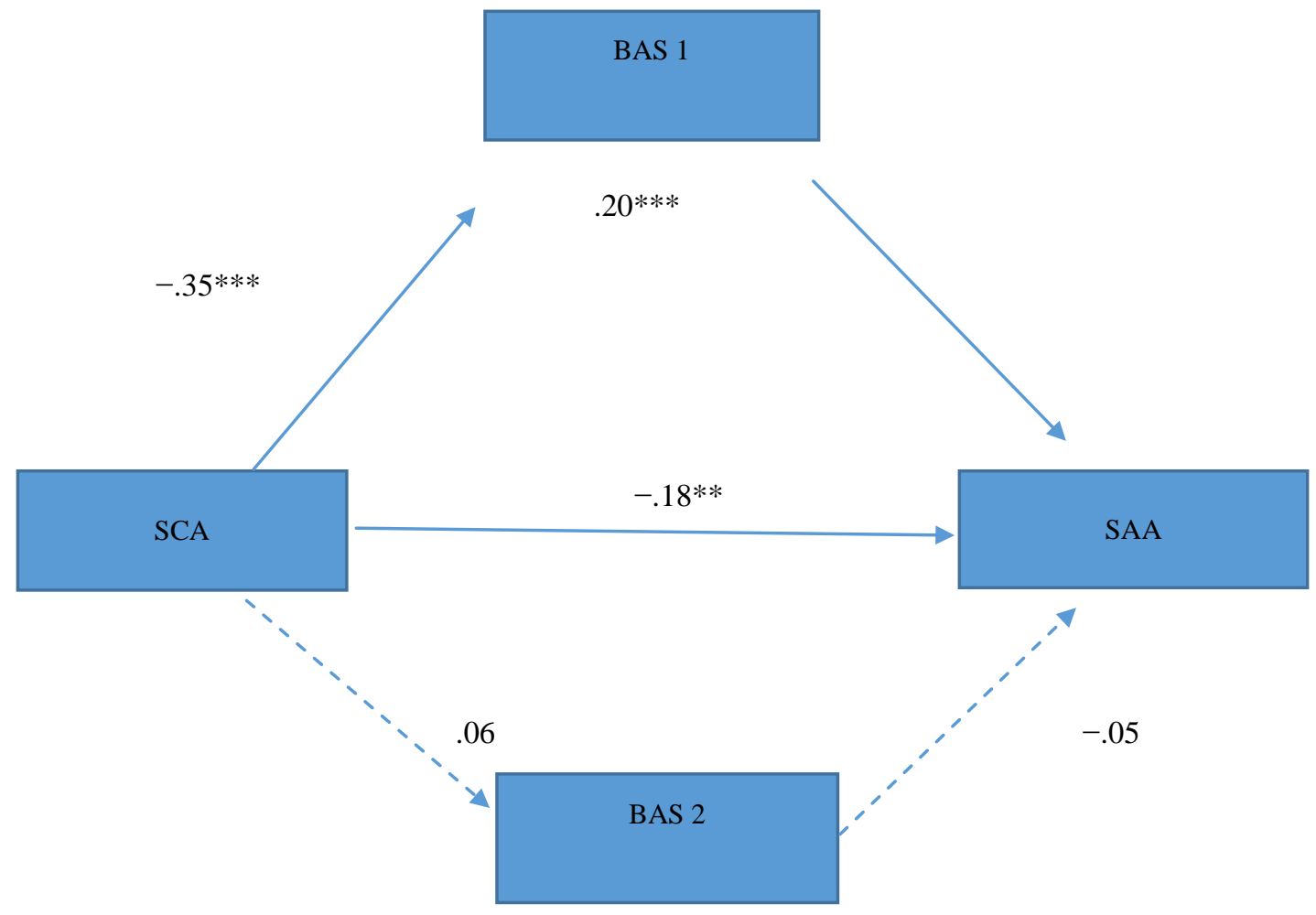

$\chi 2 / \mathrm{df}=2.62, \mathrm{IFI}=.90, \mathrm{CFI}=.90, \mathrm{TLI}=.90, \mathrm{RMSEA}=.06(\mathrm{~N}=349)$ 
B

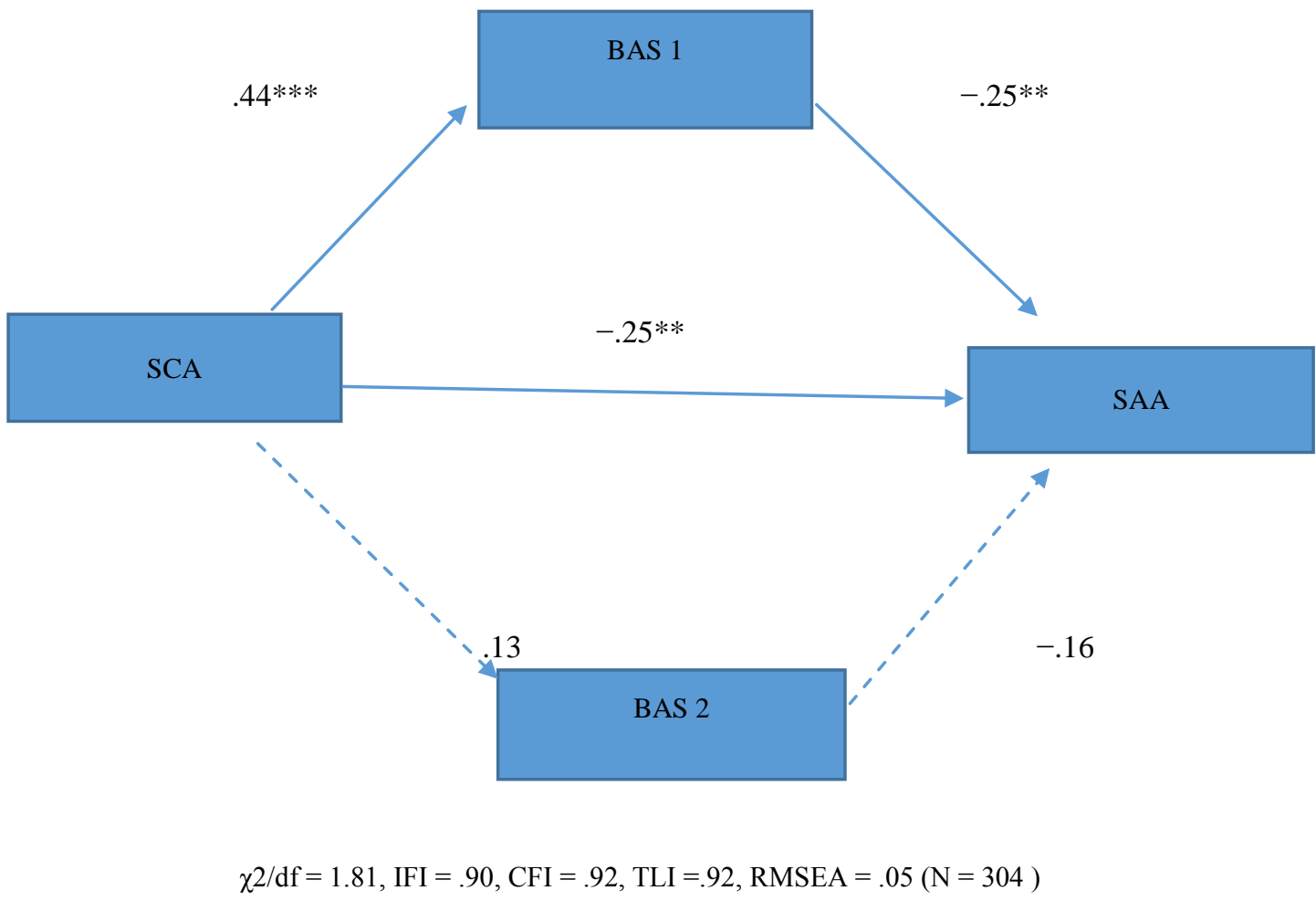

C

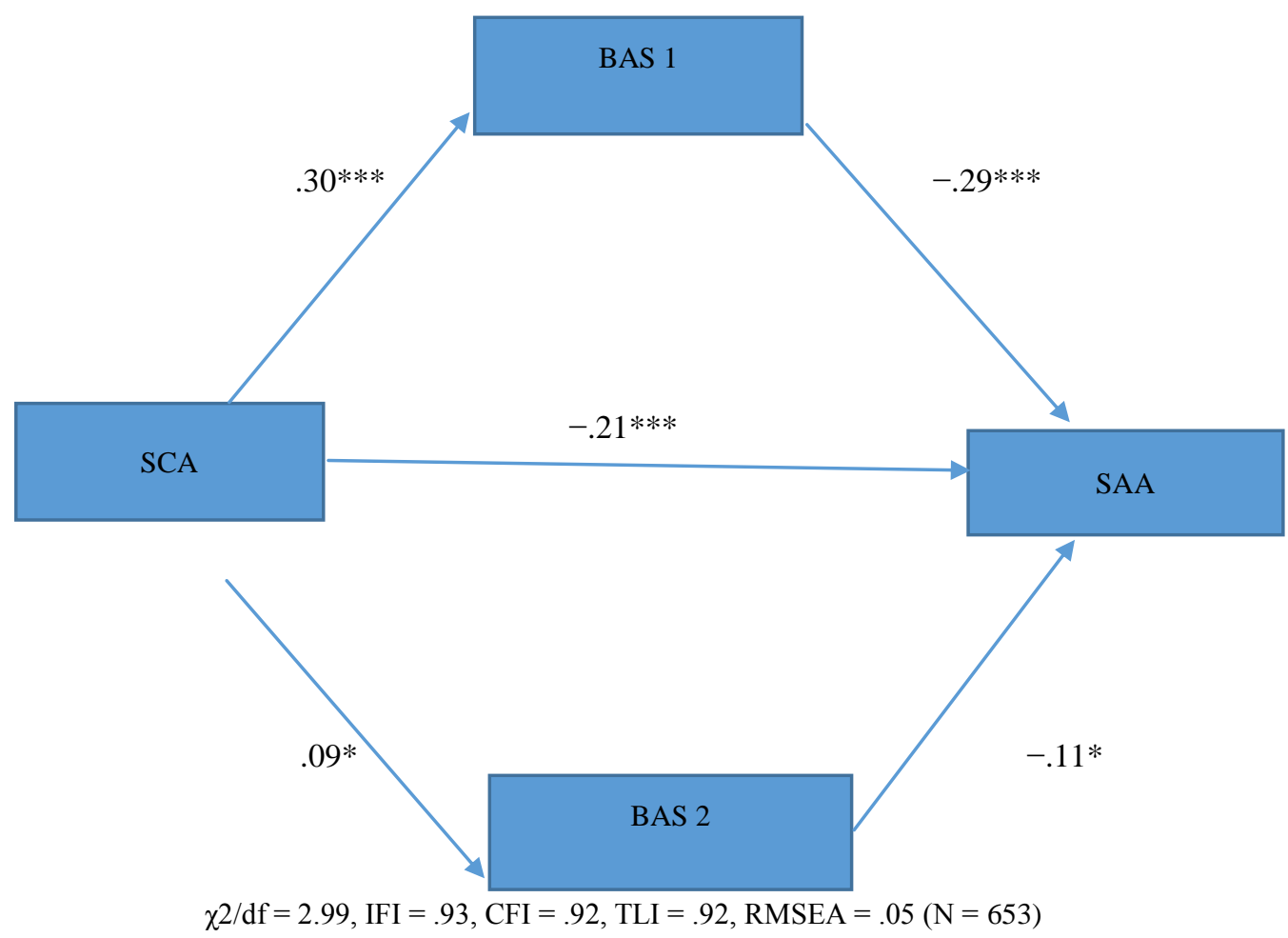

Figure 1. Results of SEM analysis among women (A), men (B), and total (C) samples. All the coefficients in the figure are standardized

Note. SCA.= Self Confident Approach, BAS 1= General Body Appreciation, BAS 2= Body Image Investment, $\mathrm{SAA}=$ Social Appearance Anxiety, $* p<0.05, * * p<0.01, * * * p<0.001$ 


\subsection{Mediation Analysis}

To test the possible mediating role bootstrapping analyses were conducted. It was applied 2000 bootstrap resamples with $95 \%$ bias-corrected confidence intervals anxiety through general body appreciation for women, men, and the total sample. As can be seen, in the women, men and total samples the indirect effect of self-confident approach on social appearance anxiety via general body appreciation was statistically significant but the indirect effect of self-confident approach on social appearance anxiety via body image investment was not statistically significant (see table 4).

Table 4. Indirect effects and $95 \% \mathrm{CI}$

\begin{tabular}{llll}
\hline Sample & Paths & Estimate & $95 \%$ bias-corrected CI \\
\hline Women $(\mathrm{n}=349)$ & $\mathrm{SCA} \rightarrow \mathrm{B} 1^{\mathrm{a}} \rightarrow \mathrm{SAA}$ & -.078 & $-.137,-.035^{* *}$ \\
& $\mathrm{SCA} \rightarrow \mathrm{B} 2^{\mathrm{b}} \rightarrow \mathrm{SAA}$ & -.015 & $-.072, .016^{\mathrm{NS}}$ \\
\hline Men $(\mathrm{n}=304)$ & $\mathrm{SCA} \rightarrow \mathrm{B} 1^{\mathrm{a}} \rightarrow \mathrm{SAA}$ & -.129 & $-.209,-.075^{* * *}$ \\
& $\mathrm{SCA} \rightarrow \mathrm{B} 2^{\mathrm{b}} \rightarrow \mathrm{SAA}$ & -.037 & $-.110, .001^{\mathrm{NS}}$ \\
\hline Total $(\mathrm{n}=653)$ & $\mathrm{SCA} \rightarrow \mathrm{B} 1^{\mathrm{a}} \rightarrow \mathrm{SAA}$ & -.104 & $-.148,-.070^{* *}$ \\
& $\mathrm{SCA} \rightarrow \mathrm{B} 2^{\mathrm{b}} \rightarrow \mathrm{SAA}$ & -.028 & $-.068, .003^{\mathrm{NS}}$
\end{tabular}

Note. CI, confidence interval. Biased-corrected bootstrap with 2000 replications. NS= not significant

$* \mathrm{p}, 0.05, * * \mathrm{p}<.005, * * * \mathrm{p}<.001$

\section{Discussion}

The present study tested the direct and indirect relations among the self-confident approach, social appearance anxiety, and body appreciation as a mediator for Turkish female and male Turkish university students. Consistent with the first hypothesis, a positive and significant correlation between the self-confident approach and body appreciation was found, as well as a significant negative correlation between the self-confident approach and social appearance anxiety for women, men and the total samples. These results are consistent with the study conducted by Avalos, Tylka, and Wood-Barcalow (2005), which indicates that body appreciation is one of the important predictors of proactive coping styles for women college students. Similarly, Jauregui-Lobero and Rios (2011) found a positive and significant correlation between adaptive coping with problems/emotions and body appreciation for male and female adolescents.

The second set of results obtained from the current study indicated a negative and significant correlation between the self-confident approach and social appearance anxiety of women, men, and the total sample. This result confirmed the second hypothesis of the research, and is compatible with the results of some previous studies (Claes et al., 2012; Kowalski et al., 2006; Niefer, McDonough \& Kowalski, 2010; Sabiston et al., 2007). The self-confident approach is a problem-focused/active coping style and generally includes an individual's taking responsibility for dealing with the source of stress, questioning his/her own role, and engaging in self-observation and a re-evaluation of his/her current situation (Şahin \& Durak, 1995). These results support that the self-confident approach is a valuable resource for coping with social appearance anxiety, and moreover, is an important factor related to body appreciation for young people.

The third result of the study is that social appearance anxiety had a negative and significant correlation to body appreciation. This result confirmed the third hypothesis of the study. Some previous studies have indicated a relationship between body image concerns and social appearance anxiety (Cash, Theriault \& Annis, 2004; Çelik, Turan \& Arıc1, 2014; Coles et al., 2006; Hart et al., 2008; Pinto \& Phillips, 2005; Sabiston et al., 2007).

To examine the fourth hypothesis of the study, the standardized path coefficients of direct and indirect relationships among the self-confident approach, social appearance anxiety, and body appreciation were analyzed. The results showed that the general body appreciation factor of BAS acts as a mediator in the relationship between the self-confident approach and social appearance anxiety for women, men, and the total sample. But, the second factor body image investment didn't act as a mediator in the relationship between the self-confident approach and social appearance anxiety. No previous studies have examined this topic. But some studies on validity of BAS showed that the Body Image Investment Factor of the Body Appreciation Scale fell below the acceptable cut-off ( $\mathrm{Ng}$, Barron \& Swami 2015; Swami \& Chamorro-Premuzic, 2008). In this research, similar result was obtained at the reliability study of BAS. For this reason it was recommended for reexamination of the Body Image Investment factor.

Consequently, the problems regarding body appreciation, may adversely affect the mental health and life quality of the individual at every period of life, particularly the adolescence (Doğan, Sapmaz \& Totan, 2011). This study revealed 
that, as similar to the Western countries, both female and male university students in Turkey have concerns for body appreciation and social appearance and the effective coping skills are important variables in overcoming these problems. Accordingly, being aware of the coping strategies preferred by the young may be important in treating the psychological disorders (anorexia nervosa, bulimia nervosa, body dysmorphic disorder) considered to be associated to the body appreciation or preserving the mental health of the young before allowing the disorders to come out.

\subsection{Strengths, Limitations and Further Research}

This study adds to the current literature on the subject by addressing the direct relationship between self-confidence and social appearance anxiety, as well as the indirect relationship between the self-confident approach and social appearance anxiety through body appreciation. In previous research, no studies have examined this subject. Moreover, the concept of body appreciation has been investigated mostly among female populations. The present study is important because it examines the ways in which both women and men cope, body appreciation, and social appearance anxiety. Also, the professionals who work with adolescents can benefit from understanding the results of this study. Helping adolescents choose problem-focused/active coping styles to deal with body dissatisfaction can make professionals' intervention strategies more effective.

As in the case with every study, this one also has several limitations. The study was carried out with only Uşak University Education Faculty students. In the future, this research model should be replicated with different sample groups in Turkey. For example, secondary school and high school students, and adults should be examined in future studies. Moreover, the literature has demonstrated that body appreciation is correlated with age, self-worth, self-esteem, optimism, well-being, mental health, and depressive symptoms (Avalos, Tylka \& Wood-Barcalow, 2005; Jauregui-Lobero \& Rios, 2011; Mele, Cazzato \& Urgesi, 2013; Rinderknecht \& Smith, 2002; Tiggemann \& McCourt, 2013). It is thought that studies that address body appreciation with these and other variables also in Turkey will enrich the research on this topic. Moreover, the model can be tested with other coping strategies such as the seeking of social support, reappraisal, a helpless approach, and a subservient approach.

In summary, the findings of this study suggest that various effective strategies for coping with anxiety that may occur as a result of body concerns are important for female and male adolescents.

\section{Conclusion and Implications}

In Turkey, the studies for the stress coping styles, body appreciation and social appearance concerns of the young are mainly conducted by the school counselor and psychological consultancy services of the schools, mainly at secondary and high schools. Schools organize seminaries in this regard and provide individual and group-based psychological consultancy support to those in need. Although the universities have psychological consultancy units, due to the lack of psychological counselors, lack of introductions to the students and the fact that they do not analyze the main consultancy issues demonstrated by the students, these units cannot ensure an adequate and qualified personal guidance and consultancy in these institutions. However, the results of this study have revealed that both female and male university students experience the problems regarding body appreciation and concern for the social appearance. It is considered that psychologists/psychological counselors working under the universities should pay attention to bodily problems and social appearance concerns of the university students considering these results in order to better functionalize the psychological counseling units in such organs.

\section{References}

American Psychiatric Association (2013). Diagnostic and Statistical Manual of Mental Disorders. APA, Washington DC, Fifth edition.

Avalos, L., Tylka, T. L. \& Wood-Barcalow, N. (2005). The body appreciation scale: development and psychometric evaluation. Body Image, 2, 285-297. http://dx.doi.org/10.1016/j.bodyim.2005.06.002

Bakalım, O \& Taşdelen-Karçkay, A. (2016). Body Appreciation Scale: evaluation of the factor structure and psychometric properties among male and female Turkish university students. Mersin University Journal of the Faculty of Education, 12(1), 410-422. http://dx.doi.org/10.17860/efd.38032.

Beauducel, A. \& Wittmann, W. W. (2005). Simulation study on fit indexes in CFA based on data with slightly distorted simple structure. Structural Equation Modeling, 12(1), 41-75. http://dx.doi.org/10.1207/s15328007sem1201_3

Çelik, E., Turan, M. E. \&Arıcı, N. (2014). The role of social appearance anxiety in meta-cognitive awareness of adolescents. International Journal of Learning, Teaching and Educational Research, 7(1). 
Cash, T. F., Santos, M. T. \& Williams, E. F. (2005). Coping with body-image threats and challenges: validation of the Body Image Coping Strategies Inventory. Journal of Psychosomatic Research, 58(2), 190-199. http://dx.doi.org/10.1016/j.jpsychores.2004.07.008

Cash, T. F., Theriault, J. \& Annis, M. (2004). Body image in an interpersonal context: Adult attachment, fear of intimacy, and social anxiety. Journal of Social and Clinical Psychology, 23, 89-103. http://dx.doi.org/10.1521/jscp.23.1.89.26987

Claes, L., Hart, T. A., Smits, D., Van den Eynde, F., Mueller, A. \& Mitchell, J. E. (2012).Validation of the social appearance anxiety scale in female eating disorder patients. European Eating Disorders Review, 20 , 406-409. http://dx.doi.org/10.1002/erv.1147

Coles, M. E., Phillips, K. A., Menard, W., Pagano, M. E., Fay, C. \& Weisberg, R. B. (2006). Body dysmorphic disorder and social phobia: Cross-sectional and prospective data. Depression and Anxiety, 23, $26-33$. http://dx.doi.org/10.1002/da.20132

Doğan, T. (2010). Sosyal Görünüş Kaygısı Ölçeği’nin (SGKÖ) Türkçe uyarlaması: Geçerlik ve güvenirlik çalışması. Hacettepe Üniversitesi Eğitim Fakültesi Dergisi, 39, 151-159.

Doğan, T., Sapmaz, F. \&Totan, T. (2011). Adaptation of the Body Image Coping Strategies Inventory to Turkish: a validity and reliability study. Anatolian Journal of Psychiatry, 12(2), 121-129.

Erol, A., Toprak, G. \& Yazıc1, F. (2006). Psychological and physical correlates of disordered eating in male and female Turkish college students. Psychiatry and Clinical Neurosciences, 60, 551-557. http://dx.doi.org/10.1111/j.1440-1819.2006.01557.x

Folkman, S.\& Lazarus, R.S. (1980). An analysis of coping in a middle-aged community sample. Journal of Social Behavior, 21, 219-239. http://dx.doi.org/10.2307/2136617

Gücüyeter, N. (2003). The Relationship between coping strategies and level of self -acceptance of high school students. Unpublished master thesis, İzmir: Dokuz Eylül University.

Güler, K. (2015). The effect of body image on life satisfaction and hopelessness among university students. Unpublished master thesis. Beykent University. İstanbul.

Halliwell, E. (2013). The impact of thin idealized media images on body satisfaction: does body appreciation protect women from negative effects. Body Image, 10, 509-514. http://dx.doi.org/10.1016/j.bodyim.2013.07.004

Hart, T. A., Flora, D. B., Palyo, S. A., Fresco, D. M., Holle, C. \& Heimberg, R. G. (2008). Development and examination of the social appearance anxiety scale. Assessment, 15(1), 48-59.doi: 10.1177/1073191107306673.

Hu, L. \& Bentler, P. (1999). Cutoff criteria for fit indices in covariance structure analysis: Conventional criteria versus new alternatives. Structural Equation Modeling, 6, 1-55.doi:10.1080/10705519909540118

Jauregui-Lobero, I.J. \& Rios, P.B. (2011). Spanish version of Body Appreciation Scale, The Spanish Journal of Psychology, 14, 411-420. http://dx.doi.org/10.5209/rev_SJOP.2011.v14.n1.37

Kalafat, T. \& Kincal, R.Y. (2008). The analysis of the interaction between the body gratification of university students and their level of skill. Dokuz Eylül Üniversitesi Buca Eğitim Fakültesi Dergisi, 23, 41-4.

Kline, P. (2013). Handbook of Psychological Testing. Routledge.

Kowalski, K. C., Mack, D. E., Crocker, P. R., Niefer, C. B. \& Fleming, T. L. (2006). Coping with social physique anxiety in adolescence. Journal of Adolescent Health, 39(2), 275-284. http://dx.doi.org/10.1177/0743558406294628

Kroon Van Diest, A. M. \&Tylka, T. L.(2010). The caregiver eating messages scale: development and psychometric investigation. Body Image, 7, 317-326. http://dx.doi.org/10.1016/j.bodyim.2010.06.002.

Kim, D. S. \& Kim, H. S. (2009). Body-image dissatisfaction as a predictor of suicidal ideation among Korean boys and girls in different stages of adolescence: A two-year longitudinal study. Journal of Adolescent Health,45(1), 47-54. http://dx.doi.org/10.1016/j.jadohealth.2008.11.017

Kurtuluş, E. (2014). Factors that influence the relationship between western media exposure and body satisfaction among Turkish university students. Unpublished master thesis. Boğaziçi University. İstanbul.

Lannantuono, A.C.\& Tylka, T. L. (2012). Interpersonal and intrapersonal links to body appreciation in college women: an exploratory model. Body Image, 9, 227-235. http://dx.doi.org/10.1016/j.bodyim.2012.01.004 
Mele, S., Cazzato, V. \& Urgesi, C. (2013). The importance of perceptual experience in esthetic appreciation of the body. PloS ONE, 8(12): e81378. http://dx.doi.org/10.1371/journal.pone.008137

Ng, S.K., Barron, D. \& Swami, V. (2015). Factor structure and psychometric properties of Body Appreciation Scale among adults in Hong Kong. Body Image, 13, 1-8. http://dx.doi.org/10.1016/j.bodyim.2014.10.009

Niefer, C. B., McDonough, M. H., and Kowalski, K. C. (2010). Coping with social physique anxiety among adolescent female athletes. International Journal of Sport Psychology, 41(4), 369.

Özmen, D., Özmen, E., Ergin, D., Çetinkaya, A. C., Şen, N., Dündar, P. E. \& Taksin, E. O. (2007). The association of self-esteem, depression and body satisfaction with obesity among Turkish adolescents. BMC Public Health, 7, 311-318. http://dx.doi.org/10.1186/1471-2458-7-80

Page, R.M. (1991). Indicators of psychosocial distress among adolescent females who perceive themselves as fat. Child Study Journal, 21, 203-211.

Pinto, A. \& Phillips, K. A. (2005). Social anxiety in body dysmorphic disorder. Body Image, 2, 401-405. http://dx.doi.org/10.1016/j.bodyim.2005.10.003

Ramseyer-Winter, V. \& Satinsky, S. (2014). Body appreciation, sexual relationship status, and protective sexual behavior in women, Body Image, 11, 36-42. http://dx.doi.org/10.1016/j.bodyim.2013.08.004

Rinderknecht, K. \& Smith, C. (2002). Body image perceptions among urban-native American youth. Obesity Research, 10, 315-327.

Sabiston, C. M., Sedgwick, W. A., Crocker, P. R. E., Kowalski, K. C. \& Mack, D. E. (2007). Social physique anxiety in adolescence: An exploration of influences, coping strategies, and health behaviors. Journal of Adolescent Research, 22(1), 78-101. http://dx.doi.org/ 10.1177/0743558406294628

Şahin, N.H. \& Durak, A. (1995). A Coping ways scale for the Turkish university students. Turkish Journal of Psychology, 10, 56-73.

Satinsky, S., Reece, M., Dennis, B., Sanders, S. \& Bardzell, S. (2012). An assessment of body appreciation and its relationship to sexual function in women. Body Image, 9, 137-144. http://dx.doi.org/10.1016/j.bodyim.2011.09.007

Schreiber, J. B., Nora, A., Stage, F. K., Barlow, E. A. \& King, J. (2006). Reporting structural equation modeling and confirmatory factor analysis results: A review. Journal of Educational Research, 99(6), 323-338. http://dx.doi.org/10.3200/JOER.99.6.323-338

Swami, V. \& Chamorro-Premuzic, T. (2008). Factor structure of the Body Appreciation Scale among Malaysian women. Body Image, 5, 409-413. http://dx.doi.org/10.1016/j.bodyim.2008.04.005

Swami, V., Campana, A. N, N. B., Fereirra, L., Barrett, S., Harris, A. S., \& Tavares, M. C. G.C. F. (2011). The Acceptance of Cosmetic Surgery Scale: Initial examination of its factor structure and correlates among Brazilian adults. Body Image, 8, 179-185. http://dx.doi.org/10.1016/j.bodyim.2011.01.001

Swami, V.\& Jaafar, J.L. (2012). Factor structure of body appreciation scale among Indonesian women and men: further evidence of a two-factor solution non-western population, Body Image, 539-542. http://dx.doi.org/10.1016/j.bodyim.2012.06.002

Swami, V., Mada, R.\& Tovée, M. J.(2012). Weight discrepancy and body appreciation of Zimbabwean women in Zimbabwe and Britain. Body Image, 9, 559-562. http://dx.doi.org/10.1016/j.bodyim.2012.05.006

Swami, V., Özgen, L., Gökçen, E. \& Petrides, K. V. (2015). Body image among female university students in Turkey: concurrent translation and validation of three body image measures. International Journal of Culture and Mental Health, 8(2), 176-191. http://dx.doi.org/10.1080/17542863.2014.917117

Tiggemann, M. \& McCourt, A. (2013). Body appreciation in adult women: relationships with age and body satisfaction. Body Image, 10, 624-627. http://dx.doi.org/10.1016/j.bodyim.2013.07.003

Yumurtac1, D. (2012). Predictors of body image among university students. Unpublished master thesis. Middle East Technical University. Ankara. 